\title{
Comparison of Endometrial Biopsy Results of Premenopausal and Postmenopausal Patients
}

\author{
Gökçe Turan ${ }^{1}$, Pınar Yalçın Bahat ${ }^{2}$, Berna Aslan Çetin², Pınar Kadiroğulları² \\ ${ }^{1}$ Medical Doctor, Gazi University, School of Medicine, Department of Obstetrics and Gynecology , Ankara, Turkey \\ ${ }^{2}$ Medical Doctor, Kanuni Sultan Suleyman Training and Research Hospital, Department of Obstetrics and Gynecology, Istanbul, \\ Turkey
}

Received: 24 February 2020, Accepted: 05 April 2020, Published online: 30 April 2020

(C) Ordu University Institute of Health Sciences, Turkey, 2019

\begin{abstract}
Objective: To evaluate the histopathological results of endometrial biopsy specimens obtained from patients who referred to our clinic with a complaint of abnormal uterine bleeding (AUB) and to compare the results of premenopausal and postmenopausal patients.

Methods: In this retrospective study, the records of patients who referred to our clinic due to AUB between 2013 and 2017, and who had undergone endometrial biopsy with pipelle were evaluated. Demographic data and menopausal status of the patients were recorded. Endometrial biopsy results of all patients were investigated. In addition, the patients were divided into two groups as premenopausal and postmenopausal. Endometrial biopsy results of both groups were compared.

Results: While $2808(56.1 \%)$ of the 5000 patients who referred with AUB and who had undergone endometrial sampling were premenopausal, $2192(43.8 \%)$ were postmenopausal. The mean age of the premenopausal and postmenopausal groups was found to be $41.6 \pm 1.8$ and $54.2 \pm 5.9$, respectively. Secretory endometrium was significantly higher in the premenopausal group than the postmenopausal group ( $\mathrm{p}$ $<0.001$ ). While atrophic endometrium and malignancy were significantly higher in the postmenopausal group than the premenopausal group, chronic endometritis was significantly higher in the premenopausal group. Conclusion: Endometrial biopsy, which is a simple, inexpensive and easy technique, is the most preferred method for the exclusion of malignancy in patients with complaint of AUB. In patients with complaint of AUB, malignancy exclusion decision by endometrial biopsy must be made considering the age interval, risk factors that may cause estrogen exposure, and menopausal status of the patients.
\end{abstract}

Key words: Pipelle, Endometrial sampling, Abnormal uterine bleeding, Premenopausal, Perimenopausal

Suggested Citation: Turan G, Yalcin Bahat P, Aslan Cetin B, Kadirogulları P. Comparison of Endometrial Biopsy Results of Premenopausal and Postmenopausal Patients. Middle Black Sea Journal of Health Science, 2020; 6(1):59-64.

Address for correspondence/reprints:

Gökçe Turan

Telephone number: +90 (533) 6745074

ORCID-ID: 0000-0002-2443-1927

E-mail: drgokceturan@gmail.com

DOI: $10.19127 / \mathrm{mbsjohs.693457}$

\section{Introduction}

Abnormal uterine bleeding (AUB) accounts for about one-third of the referral reasons to the outpatient clinic in gynecology practice (Turan et al. 2018). PALM-COEIN acronym, which is used for the classification of uterine bleeding abnormalities according to hemorrhagic pattern and etiology in women of reproductive age, was introduced by the International Federation of Gynecology and Obstetrics (FIGO) in 2011. While PALM is classified as polyp, adenomyosis, leiomyoma, malignancy, and hyperplasia; COEIN is classified as coagulopathy, 
ovulatory dysfunction, endometrial causes, iatrogenic and not yet classified (Munro et al. 2011).

As well as endometrial biopsy is a safe and effective diagnostic method in women with complaint of AUB, its main purpose is to eliminate malignancy. Nearly $80 \%$ of endometrial biopsies taken due to AUB are benign both in premenopausal and postmenopausal women. When the endometrial biopsy results of premenopausal and postmenopausal women with complaint of AUB are considered, while the rate of malignancy in premenopausal women is $0.4 \%$, it raises up to $7 \%$ in postmenopausal women (Brinton et al. 2013; Jayawickcrama \& Abeysena 2019). Approximately $2 / 3$ of the women who undergo hysterectomy are women with AUB complaints (Kotdawala et al. 2013). Depending on the physician's preference or patient's suitability, abdominal, vaginal or laparoscopic hysterectomy can be performed (Peker et al. 2019).

The aim of our study is to evaluate the histopathological results of endometrial biopsy specimens obtained from patients who referred to our clinic with complaint of AUB and to compare the results of premenopausal and postmenopausal groups.

\section{Methods}

Patients older than 40 years who had undergone endometrial biopsy with pipelle due to complaint of between January 2013 and January 2017 were included in the study. After the approval of our hospital's ethics committee (ethics committee no: 2018.9.08), the study was planned retrospectively.

Patients who had undergone curettage for obstetric reasons, patients with previously known genital system malignancies, patients whose endometrial biopsy results were reported as just blood and mucus or inadequate material, were excluded from the study. Patients who did not receive any treatment due to abnormal uterine bleeding were included in the study. The patients were divided into two groups as premenopausal and postmenopausal. Age, gravida, parity, abortus, body mass index (BMI) and endometrial biopsy results of the patients in both groups were recorded. Patients who had no period for a year or more were accepted as postmenopausal. Endometrial biopsy samplings of all patients were performed under local anesthesia and pipelle curettage was performed in all. Collected endometrial biopsy materials were kept in $10 \%$ formal saline. Biopsy reports were evaluated by the pathologists of our hospital. The results were recorded as benign (proliferative and secretory endometrium, endometrium under progesterone effect, endometrium under estrogen effect, endometrial polyp), malignant and hyperplasia (complex, simple).

The Statistical Package for Social Sciences 20.0 (SPSS Inc.; Chicago, IL, the USA) was used for the statistical analysis of the study data. The distribution of the data was evaluated with the KolmogorovSmirnov Test. The descriptive statistical methods (mean and standard deviation) were used in evaluating the normally-distributed data, and the Independent $\mathrm{t}$-test was used to compare the paired groups. The one-way Chi-square test were used for comparison between categorical variables. The results were evaluated at $p<0.05$ significance level.

\section{Results}

A total of 5850 biopsy specimens obtained from endometrial sampling due to complaint of AUB were investigated. A total of 5000 patients fulfilling the study criteria were included in the study. When the endometrial sampling results of all patients were investigated, endometrial biopsy results of 1142 $(22.8 \%)$ of the 5000 patients were found to be endometrium under progesterone effect, whereas endometrial polyp $(22.2 \%)$ was the second most common endometrial biopsy result in the general population, leiomyoma was the rarest $(0.1 \%)$. While $2808(56.1 \%)$ of the patients were premenopausal, $2192(43.8 \%)$ were postmenopausal, whereas the mean age of all the patients was $44,7 \pm 8,06$, the mean age of premenopausal and postmenopausal groups were found to be $41.6 \pm 1.8$ and $54.2 \pm 5.9$, respectively. Age, gravida, parity, abortus numbers and BMI of the groups are listed in Table-1. While the gravida numbers of the patients in the postmenopausal group were significantly higher than the premenopausal group, there was no difference between parity, abortus numbers and, BMI values. When the endometrial biopsy results of both groups were considered (Table-2), while endometrium under progesterone effect (premenopausal and postmenopausal were $22.4 \%$ and $23.3 \%$, respectively) was found to be the most common endometrial biopsy result in both groups, endometrial polyp (premenopausal and postmenopausal were $\% 21.9$ and $\% 22.5$, respectively) was the second most common result. There was no difference between the groups in terms of endometrium under progesterone effect, endometrium under estrogen effect, endometrial polyp, endometrial hyperplasia, proliferative endometrium, malign mesenchymal tumor and leiomyoma ( $>0.05)$. The secretory endometrium was significantly higher in the premenopausal group than the postmenopausal group $(\mathrm{p}<0.001)$. While atrophic endometrium and 
malignancy were significantly higher in the postmenopausal group than the premenopausal group, chronic endometritis was significantly higher in the premenopausal group.

Table 1. Demographic Data of Patients

\begin{tabular}{lllll}
\hline Demographic data & $\begin{array}{l}\text { All patients } \\
\mathbf{n = 5 0 0 0}(\mathbf{\%} \mathbf{1 0 0})\end{array}$ & $\begin{array}{l}\text { Premenopausal } \\
\mathbf{n = 2 8 0 8}(\mathbf{\% 5 6 , 1})\end{array}$ & $\begin{array}{l}\text { Postmenopausal } \\
\mathbf{n = 2 1 9 2}(\mathbf{\% 4 3 , 8})\end{array}$ & $\mathbf{P} *$ \\
\hline Age & $44,7 \pm 8,06$ & $41,6 \pm 1,8$ & $54,2 \pm 5,9$ & $\mathbf{0 , 0 0 2}$ \\
\hline Gravida & $3,87 \pm 0$ & $3 \pm 2,1$ & $4,75 \pm 2,2$ & $\mathbf{0 , 0 0 1}$ \\
\hline Parity & $3 \pm 2$ & $3,3 \pm 1,8$ & $2,6 \pm 1,7$ & 0,500 \\
\hline Abortus & $1 \pm 0,9$ & $0,8 \pm 1,2$ & $1,2 \pm 0,8$ & 0,500 \\
\hline BMI $(\mathbf{k g} / \mathbf{m})$ & $32,5 \pm 8,5$ & $32,6 \pm 8,8$ & $32,4 \pm 8,3$ & 0,900
\end{tabular}

*Premenopausal and postmenopausal patients are compared.

Table 2. Comparison of the Endometrial Biopsy Results of Premenopausal and Postmenopausal Groups

\begin{tabular}{|c|c|c|c|}
\hline Endometrial biopsy results & $\begin{array}{l}\text { Premenopausal } \\
(\mathrm{n}=2808)\end{array}$ & $\begin{array}{l}\text { Postmenopausal } \\
(n=2192)\end{array}$ & $\mathbf{P}$ \\
\hline $\begin{array}{l}\text { Effect of Progesterone } \\
(n=1142, \% 22,8)\end{array}$ & $631(\% 22,4)$ & $511(\% 23,3)$ & 0.470 \\
\hline $\begin{array}{l}\text { Effect of Estrogen } \\
(n=465, \% 9,3)\end{array}$ & $281(\% 10)$ & $184(\% 8,3)$ & 0.053 \\
\hline $\begin{array}{l}\text { Endometrial polyp } \\
(\mathrm{n}=1112, \% 22,2)\end{array}$ & $617(\% 21,9)$ & $495(\% 22,5)$ & 0.650 \\
\hline $\begin{array}{l}\text { Simple-complex hyperplasia } \\
(\mathrm{n}=\mathbf{5 2 7}, \% \mathbf{1 0 , 5})\end{array}$ & $291(\% 10,3)$ & $236(\% 10,7)$ & 0.637 \\
\hline $\begin{array}{l}\text { Secretory endometrium } \\
(\mathrm{n}=496, \% 9,9)\end{array}$ & $357(\% 12,7)$ & $139(\% 6,3)$ & $<0.001$ \\
\hline $\begin{array}{l}\text { Proliferative endometrium } \\
(\mathrm{n}=812, \% 16,2)\end{array}$ & $476(\% 16,9)$ & $336(\% 15,3)$ & 0.126 \\
\hline $\begin{array}{l}\text { Atrophic endometrium } \\
(n=206, \% 4,1)\end{array}$ & $27(\% 0,9)$ & $179(\% 8,1)$ & $<0.001$ \\
\hline $\begin{array}{l}\text { Chronic endometritis } \\
(n=169, \% 3,3)\end{array}$ & $108(\% 3,8)$ & $61(\% 2,7)$ & 0.040 \\
\hline $\begin{array}{l}\text { Malignancy } \\
(\mathrm{n}=60, \% 1,2)\end{array}$ & $14(\% 0,4)$ & $46(\% 2)$ & $<0.001$ \\
\hline $\begin{array}{l}\text { Malign mesenchymal tumor } \\
(n=7, \% 0,14)\end{array}$ & $4(\% 0,14)$ & $3(\% 0,13)$ & 0.900 \\
\hline $\begin{array}{l}\text { Leiomyoma } \\
(\mathrm{n}=5, \% 0,1)\end{array}$ & $2(\% 0,07)$ & $2(\% 0,09)$ & 0.071 \\
\hline
\end{tabular}

\section{Discussion}

In our study, histopathological results of patients who presented with complaint of AUB and who had undergone endometrial biopsy with pipelle were investigated and the results of premenopausal and postmenopausal patients were compared. While atrophic endometrium and malignancy were significantly higher in the postmenopausal group, secretory endometrium and chronic endometritis were significantly higher in the premenopausal group. Being one of the most common referral reasons to gynecology outpatient clinics, AUB affects $10-35 \%$ of women of reproductive age, whereas approximately $50 \%$ of postmenopausal women are affected (Turan et al. 2018). According to PALMCOEIN classification, the most common reasons for AUB are myoma, polyp and endometrial cancer (Munro et al. 2011). In 2013, it was reported by ACOG that endometrial biopsy is required for malignancy exclusion in women older than 45 with complaint of AUB or younger than 45 with estrogen exposure (Wright et al. 2017). As well as endometrial 
cancer is the most common gynecologic malignancy, its most common symptom is AUB. While endometrial cancer is observed in $70 \%$ of postmenopausal and $25 \%$ of premenopausal women in general, it is seen in $10-15 \%$ of postmenopausal patients referring with AUB (Dangal 2003).

In a study conducted by Abdullah et al., consisting of 2295 patients with complaint of AUB, proliferative endometrium was found to be present in $21.7 \%$ of patients, secretory endometrium in $24.9 \%$, endometrial polyp in $9.9 \%$, atrophic endometrium in $3.1 \%$, malignancy in $1.8 \%$, chronic endometritis in $5.8 \%$ and endometrial hyperplasia in $9.1 \%$ (Abdullah $\&$ Bondagji 2011). In our study, when the distribution of patients presenting with complaint of AUB are considered, proliferative endometrium is found to be present in $16.2 \%$ of patients, secretory endometrium in $9.9 \%$, endometrial polyp in $22.2 \%$, atrophic endometrium in $4.1 \%$, malignancy in $1.2 \%$, chronic endometritis in $3.3 \%$ and endometrial hyperplasia in $10.5 \%$

In a study conducted by Burbos et al., the rate of malignancy was found to be $5.8 \%$ in 4454 postmenopausal women with complaint of AUB (Burbos et al. 2012). Similarly, the rate of malignancy in the study conducted by Ewies et al. in postmenopausal patients was found to be $5.5 \%$ (Ewies, A. A., Musonda 2010). In a study conducted, endometrial cancer was detected in $0.4 \%$ of premenopausal who presented with AUB whereas the rate was 7\% in postmenopausal women (Britton et al. 2019). In our study, while malignancy was detected in $0.42 \%$ of premenopausal patients with complaint of AUB, it was detected in $2 \%$ of postmenopausal patients. This rate occurs to be lower compared to data in literature. This can be explained by the presence or absence of endometrial cancer risk factors. The probability of endometrial cancer increases in patients with risk factors such as anovulation, obesity, nulliparity, diabetes and tamoxifen treatment (Britton et al. 2019). However, in our study, enough data on additional risk factors in the patient groups could not be retrieved.

In the study conducted by Jairajpuri et al., in which endometrial sampling was performed with $D \& C$ on 219 perimenopausal patients aged 40-50, with complaint of AUB, endometrial polyp was detected in $2.7 \%$ of the patients (Jairajpuri et al. 2013). In our study, the incidence of endometrial polyp was higher both totally and individually in each of the two groups than in the study by Jairajpuri et al. The reason for this difference may be due both to the higher number of patients in our study and to endometrial sampling being performed with pipelle curettage rather than
$\mathrm{D} \& \mathrm{C}$, meaning the technical difference. In addition, since the endometrial polyp may be focally located, the diagnosis may not always be possible with endometrial sampling. In the same study, most common pathology was found to be secretory endometrium (Jairajpuri et al. 2013). In our study, the most common endometrial biopsy result observed both in the premenopausal and postmenopausal groups was endometrium under progesterone effect. In addition, the difference of our study from the study of Jairajpuri et al. is that the premenopausal and postmenopausal groups were investigated separately and both groups were compared.

While chronic endometritis was found to be $6.4 \%$ in a study conducted by Khare et al., in which endometrial sampling was performed on patients with complaint of AUB (Khare, A., Bansal, R. 2012), it was reported as $20.7 \%$ in a similar study by Michail et al. (Michail et al. 2007). In case of our study, chronic endometritis was observed in 169 patients (3.3\%) of 5000 patients (108 patients in the premenopausal group (3.8\%) and 61 patients in the postmenopausal group (2.7\%)). A higher rate of chronic endometritis was observed in both studies than our study. In our study, chronic endometritis was found to be significantly higher in the premenopausal group than in the postmenopausal group. The reason for the presence of more cases in the premenopausal group may be since the sexually-active period is more prevalent in this age group. The reason why the chronic endometritis was detected less in the present study of ours compared to the data in the literature may be the rates of polygamy or monogamy, which show differences among countries, and the different prevalence of infections among countries.

Endometrial hyperplasia was detected in 15 patients (15\%) in a study by Takreem et al., consisting of 100 perimenopausal patients with complaint of AUB (Takreem et al. 2009). In the study by Khare et al., this rate increased up to $51 \%$ (Khare, A., Bansal, R. 2012). In our study, endometrial hyperplasia was observed in $10.3 \%$ premenopausal and $10.7 \%$ of postmenopausal patients. Although this rate is below the rates in literature, it may still be considered as close to the literature rates. In this study, there are some failures in the analysis of the endometrial hyperplasia results due to the lack of enough data retrieval and therefore the results of endometrial hyperplasia could not be divided into subgroups in detail. When the numbers of endometrial hyperplasia in our study (without dividing to subgroups) were considered, no difference was observed between the two groups. 
The limitation of our study is that, because it is a retrospective study some data could not be retrieved. However, the strength of our study is the large number of cases and the comparison of the results according to the menopausal status.

\section{Conclusion}

The main purpose of endometrial biopsy is to reveal the organic pathology that may cause ARF. Endometrial biopsy, which is a simple, inexpensive and easy technique for diagnosis, is the most preferred method. In patients with AUB complaints, it should be decided to exclude the AUB. Nowadays, endometrial biopsy, which is a simple, inexpensive and easy technique, is the most preferred method for diagnosis. In patients with complaint of AUB, malignancy exclusion decision by endometrial biopsy must be made considering the age interval, risk factors that may cause estrogen exposure, and menopausal status of the patients. In our study, more frequent occurrence of endometrial cancer in postmenopausal patients also supports this situation.

Ethics Committee Approval: Ethics committee approval was received for this study from Clinical Research Ethics Committee of Health Science University, Kanuni Sultan Suleyman Training and Research Hospital (ethics committee no: 2018.9.08)

Peer-review: Externally peer-reviewed.

Author Contributions: Concept - GT, BAÇ; Design- GT; Supervision- BAC; Materials - PYB, PK ; Data Collection and/or Processing- PYB; Analysis and/or Interpretation -GT, BAC; Literature Review -PK, PYB; Writing - GT ; Critical Review BAC

Conflict of Interest: No conflict of interest was declared by the authors.

Financial Disclosure: The authors declared that this study hasn't received no financial support.

\section{References}

Abdullah LS, Bondagji NS. Histopathological pattern of endometrial sampling performed for abnormal uterine bleeding. Bahrain Med. Bull. 2011;33(4):195-98.

Brinton LA, Felix AS, McMeekin DS, Creasman WT, Sherman ME, et al. Etiologic heterogeneity in endometrial cancer: Evidence from a Gynecologic Oncology Group trial. Gynecol. Oncol. 2013;129(2):277-84.
Britton H, Huang L, Lum A, Leung S, Shum K, Kale $\mathrm{M}$ et al. Molecular classification defines outcomes and opportunities in young women with endometrial carcinoma. Gynecol. Oncol. 2019;153(3):487-95.

Burbos N, Musonda P, Crocker SG, Morris EP, Duncan TJ, Nieto JJ. Outcome of investigations for postmenopausal vaginal bleeding in women under the age of 50 years. Gynecol. Oncol. 2012;125(1):120-23.

Dangal G. A study of endometrium of patients with abnormal uterine bleeding at Chitwan Valley. Kathmandu Univ. Med. J. (KUMJ). 2003;1(2):110-12

Ewies, A. A., Musonda P. Managing postmenopausal bleeding revisited: What is the best first line investigation and who should be seen within 2 weeks? A cross-sectional study of 326 women. Eur. J. Obstet. Gynecol. Reprod. Biol. 2010;153(1):67-71.

Jairajpuri Z, Jetley S, Rana S. Morphological spectrum of endometrial pathology in middleaged women with atypical uterine bleeding: A study of 219 cases. J. Midlife. Health. 2013;4(4):216.

Jayawickcrama WIU, Abeysena C. Risk factors for endometrial carcinoma among postmenopausal women in Sri Lanka: a case control study. BMC Public Health. 2019;19(1):1387.

Khare, A., Bansal, R. E a. Morphological spectrum of endometrium in patients presenting with dysfunctional uterine bleeding. People's J Sci Res. 2012;5(2):13-16

Kotdawala P, Kotdawala S, Nagar N. Evaluation of endometrium in peri-menopausal abnormal uterine bleeding. J. Midlife. Health. 2013;4(1):16

Michail G, Karahaliou A, Skiadopoulos S, Kalogeropoulou C, Terzis G, Boniatis, I. et al. Texture analysis of perimenopausal and postmenopausal endometrial tissue in grayscale transvaginal ultrasonography. Br. J. Radiol. 2007;80(956):609-16.

Munro MG, Critchley HOD, Broder MS, Fraser IS. FIGO classification system (PALM-COEIN) for causes of abnormal uterine bleeding in nongravid women of reproductive age. Int. J. Gynecol. Obstet. 2011;113(1):3-13.

Peker N, Aydin E, Yavuz M, Bademkiran MH, Ege $\mathrm{S}$, et al. Factors associated with complications of vaginal hysterectomy in patients with pelvic organ prolapse - a single centre's experience. Ginekol. Pol. 2019;90(12):692-98 
Takreem A, Danish N, Razaq S. Incidence of endometrial hyperplasia in 100 cases presenting with polymenorrhagia/menorrhagia in perimenupausal women. J. Ayub Med. Coll. Abbottabad. 2009;21(2):60-63

Turan G, Yalcin Bahat P, Aydin A, Yuksel Ozgor B. Evaluation of platelet-rich plasma injection activity in the treatment of abnormal uterine bleeding. J. Turkish Soc. Obstet. Gynecol. 2018;15(4):222-26.

Wright JD, Chen L, Gabor L, Burke WM, Tergas AI, et al. Patterns of Specialty-Based Referral and Perioperative Outcomes for Women with Endometrial Cancer Undergoing Hysterectomy. Obstet. Gynecol. 2017;130(1):81-90. 